\title{
Tollensing van Inwagen
}

Van Inwagen (1990) has an ingenious argument for the non-existence of human artefacts (and other non-living complex things). But the argument cannot be accepted, since human artefacts are everywhere. ${ }^{1}$ However, it cannot be ignored. The proper response to it is to treat it as a refutation of its least plausible premise, i.e., to 'tollens' it. In the following I first set out van Inwagen's argument. I then identify its least plausible premise and explain the consequence of denying it. I argue that denying it is not so difficult, since on reflection its denial is an easy consequence of ordinary beliefs. I finish by explaining why, despite his best efforts, van Inwagen has not persuaded me that it may be true that artefacts do not exist and conclude that nothing stands in the way of tollensing van Inwagen and accepting the consequence of doing so.

Van Inwagen's argument for the non-existence of artefacts can be set out as follows. If I touch shoulders with someone in a crowd, or shake hands with them, nothing new comes into existence as a result of our encounter. If we become momentarily paralysed as we shake hands, still nothing new comes into existence. The same is true if we become glued together or tied together as we shake hands, or even if our flesh is melted so that no boundary is discernible between us. In all these cases of contact or various kinds of bonding nothing new of which we are parts is brought into existence as a result of our coming to be so related.

But the relations just identified include all the kinds of spatial and causal relations which are created between bits of wood when, as we would ordinarily say, a chair is made. However, "whether certain objects add up to or compose a larger object does not depend on anything besides the spatial and causal relations they bear to one another' (van Inwagen 1990: 12, this is van Inwagen's tenth listed constraint on his theorizing). For example,

\footnotetext{
${ }^{1}$ Of course, the sceptic about the external world will deny my claim to know this. But this is no help to van Inwagen. His claim is not that I do not know that human artefacts exist, but that they do not, though there are material particles, some arranged 'chairwise', some 'tablewise' etc. (and plants and animals). This is equally open to challenge by the external world sceptic.
} 
nothing outside the region of space containing some bricks is relevant to the question whether there is anything they compose; and, in particular, the beliefs, attitudes and interests of any persons are irrelevant. This may be admitted, it may be rejoined to van Inwagen, but it may still be said that you and I, however bonded, do not compose a third object, whilst the bits of wood glued and tied together compose a chair, because it matters for whether composition takes place not only what relations obtain between the putative parts, but also what kind of thing they are; and bonding relations sufficient for composition to occur when things of one kind (e.g., bits of wood) are so bonded need not be sufficient for composition to occur when things of a distinct kind (say, people) are so bonded, even if things are of the latter kind can be bonded exactly as things of the former kind are when they compose something. But this rejoinder is deeply implausible, for as van Inwagen notes, '[one might say] that if inanimate objects are fastened to one another, they thereby compose something, but that if living organisms are fastened to one another, they nevertheless do not compose anything. But what could justify such discrimination; if the operation fastening has the power to turn inanimate objects into the parts of a whole, why doesn't this operation have the same power with respect to living organisms?' (van Inwagen 1990: 68). ${ }^{2}$

But if a new thing composed of bits of wood is not brought into existence when bits of wood are bonded together in the sort of way we describe as 'making a chair', no chairs have ever been made, and if no chairs have ever been made there never have been any chairs, or, of course, any other human artefacts.

As I said, I think that this is an ingenious argument. But its conclusion is false. So the appropriate response is to regard it as a refutation of its least plausible premise. This is the

\footnotetext{
${ }^{2}$ The plausibility of the thought behind the rhetorical question here - that if you can make an artefact of a certain kind out of certain inanimate components, you can make an artefact of that same kind out of animate components, as long as they are capable of performing the right functional job - is illustrated by the example given below of the whip made of snakes.
} 
contention that when people come to be bonded nothing new comes into existence of which they are parts.

Suppose we deny this. Then we have to say that when you and I come to be bonded together in one of the ways described a new thing comes into existence of which we are parts. And, of course, we must accept that whenever any things becomes so bonded together, whatever kind or kinds of thing they are, something new is brought into existence of which they are parts. So far this does not require us to say that when two people merely come into contact they come to compose something new. But this conclusion is not far away. For, of course, I can make an artefact, e.g., a child's wooden brick house, merely by bringing objects into contact (and the house may last only for the space of a handshake if the child is bored and naughty). Van Inwagen's argument can be used to conclude that I cannot, since people do not come to compose something new just when they come into contact. But it is just as false that no one has ever made a toy house out of wooden bricks as that no one has ever made a chair, so we must reverse van Inwagen's reasoning and conclude that when two people come into contact something new comes into existence. Hence, we must conclude, whenever two things, of any kind or kinds, come into contact something new, of which they are parts, comes into existence.

Thus reversing van Inwagen's reasoning leads to a plenitudinous ontology. However, it does not immediately commit one to Universalism, the thesis that necessarily, if things are disjoint there is a whole they compose. But this thesis is not a great reach now, and certainly using the reversal of van Inwagen's reasoning it is easy to conclude that things, inanimate or animate, can compose a whole without being in contact, for some artefacts (or other products of intentional human activity) ${ }^{3}$ consist of disconnected parts (and, of course, as van Inwagen

\footnotetext{
${ }^{3}$ Rock gardens; bird cages consisting of magnetically suspended and spatially separated bits of wire, space stations with separated living quarters and ablution blocks, the USA.
} 
notes (1990: 34), ${ }^{4}$ anyone who is moderately scientifically educated and believes in nonliving composites at all, will say this is true of atoms and molecules and all the things they compose). And if contact is not necessary, albeit sufficient, what can be necessary? But Universalism, together with the doctrine of plenitude, entails (a weak form of) pluralism, the thesis that two non-identical things can share all their parts at a time (though not necessarily at all times). Van Inwagen denies this thesis, but it seems to be the natural conclusion if his argument is reversed in the way recommended.

But is not the claim that no new object comes into existence when two people are bonded utterly plausible? Actually, I think not. Van Inwagen allows (1990: 35) that it is plausible that when one builds a model of Salisbury Cathedral out of wooden blocks one has brought into existence something they compose. And he will not deny that when the cue ball rebounds from the eight ball a short-lived object is created (he says that there may be no answer to the question laid up in heaven). But he insists later: 'it is pretty clear that one cannot bring a composite object into existence by bonding two human beings - or two living organisms of any sort - to each other. And the corresponding thesis about any number of human beings would also seem to be true' (van Inwagen 1990: 62). And he adds in a rhetorical footnote 'Try to imagine bringing something into existence by gluing hamsters or snakes together' (van Inwagen 1990: 287).

But nothing is easier. Van Inwagen himself at one point imagines weaving a very long, thin, tough snake into a hammock. Imagine instead tying together two or more shortish, flexible snakes to make a whip. Anyone who believes that we can create artefacts at all must allow that we can do this. But now imagine another possible world, in which perhaps there are no human beings at all, but the snakes come to be bound together by accident, by 'cosmic

\footnotetext{
4 '... it is undeniably true that, if there are any composite material objects at all, they are composed of elementary particles and the elementary particles that compose a given material object are not in contact.'
} 
coincidence' as it were. If we accept van Inwagen's thesis that whether certain objects add up to or compose some larger object does not depend on anything besides the spatial and causal relations which they have to one another, which I think is not just an assumption of van Inwagen's but something that is appealing to common-sense also, we must say that in this other possible world too there is an object composed of the snakes - though, of course, it is not a whip, since to be a whip is to be something created by human beings with flagellatory intentions, or at least something used by human beings for a flagellatory purpose, i.e., to be a whip is to possess a certain relational property which the whole composed of the snakes in the 'cosmic coincidence' world does not possess.

However, if something comes into existence when some snakes get entangled, whether or not any human agency is involved, equally something comes into existence when two men are bound together, whether or not human agency is involved. ${ }^{5}$ And since it is obvious that one can make an artefact, with suitable intentions, just by bringing some living things into contact (one might stuff a mattress with hamsters, though it would be useful to sedate them first to stop them wriggling), by the same reasoning one can conclude that their merely coming into contact is enough to make two human beings parts of a new whole. ${ }^{6}$

So, I claim, it is a fairly easy consequence of premises that are appealing to commonsense - i.e., the general assumptions van Inwagen's own argument relies on, together with the

\footnotetext{
${ }^{5}$ So, it should be noted, van Inwagen's only argument that fastening does not suffice for composition collapses, since it rests on the false claim that 'it is certainly not true that an object composed of you and me comes into existence at the instant our [entwined] fingers become paralysed' (1990: 58).

${ }^{6}$ But then, why has van Inwagen's initial 'handshake' example (1990: 35) encountered so little resistance? When people touch shoulders, or shake hands then, in the absence of appropriate intentions, no new artefact is brought into existence (contrast, a wall of policemen standing shoulder to shoulder again rioters, a Conga line, a handshake posed for painting or sculpting). Nor is the short-lived object such free, unconstrained, human agents compose easily conceived as usable as an artefact (unlike rocks, mountains and molecules, arrangements of wooden bricks, accidentally entangled snakes, or objects composed of people glued together or 'daisy-chained' together by a mad surgeon (van Inwagen 1990: 59)). But we tend to ignore things we cannot see as having a purpose or being in some way usable for a purpose. However, whether or not this is true, it remains that it is an easy consequence of our everyday beliefs that there is something that comes into being whenever people come into contact - even if we are not disposed, in certain cases, to accept it, or even disposed to reject it.
} 
thought he oddly rejects, that it is no more difficult to make composite objects out of living beings than out of non-living beings - that when people are bonded together, or even merely brought into contact, new things come into existence.

I said that I would finish by explaining why I am not persuaded by van Inwagen's attempt to explain why his conclusion that there are no artefacts, or non-living complexes generally, is not just to be rejected out of hand (see also Hirsch, 1993).

This thesis is part of what van Inwagen calls 'the Denial', and he argues strenuously that the Denial does not contradict our ordinary beliefs. ${ }^{7}$ His most careful attempt to do this appeals to the fable of the bligers. I think that we can see why van Inwagen's thesis is unacceptable by seeing how the analogy he attempts to draw fails.

Van Inwagen takes great care to explain, as clearly as he can, what, in his view, the Denial means:

There are certain properties a thing would have to have to be properly called a 'table' on anyone's understanding of the word, and nothing has all of these properties. If anything did have them it would be real, a true object, actually a thing, a substance, a unified whole, and something more than a collection of particles. But nothing does. If there were tables they would be composite material objects, and every composite material object is real, a true object, actually a thing, a substance, a unified whole, and something more than a collection of particles. But there are no tables. (1990: 100) Nevertheless, van Inwagen thinks, the Denial as he means it, speaking as a metaphysician (1990: 101), is consistent with what we commonly mean, not speaking as metaphysicians, when we say such things as 'there are two valuable eighteenth century antique tables in the next room'. For any of the propositions that an English speaker might

\footnotetext{
${ }^{7}$ Others (e.g., Merricks) deny the existence of artefacts but do not attempt this reconciliation. They are not the topic of this paper. I think that the premises of their arguments are as easily deniable as van Inwagen's. However, my main aim is not to engage in this dispute but to get clear about the (plenitudinous, pluralist) ontological commitment of everyday belief.
} 
express by uttering this sentence on a particular occasion is consistent with the proposition that he, van Inwagen, expresses by saying, speaking metaphysically, 'there are no tables'.

But are these propositions consistent with what English speakers, not speaking metaphysically, express by uttering 'there are no tables'? If so, what an ordinary English speaker expresses by 'there are two valuable eighteenth century antique tables in the next room' does not entail what he would express, not speaking metaphysically, by uttering 'There are tables'. Does it then entail what he would express, not speaking as a metaphysician, by 'there are two valuable antique tables in the next room', 'there are two valuable tables in the next room', 'there are antique tables', 'there are valuable tables', 'there are tables in the next room', 'there are still some eighteenth century tables in existence', 'there are still (postnuclear holocaust) some tables in existence (though no chairs)' - where does one draw the line? It seems both an extraordinary claim that the entailment does not hold and one that van Inwagen never actually attempts to defend. But suppose, on the other hand, that what ordinary English speakers, not speaking metaphysically, would express by uttering 'There are tables' is entailed by the propositions they would express on particular occasions, also not speaking metaphysically, by uttering 'There are two valuable eighteenth century antique tables in the next room'. In that case van Inwagen's metaphysical assertion 'There are no tables' does not contradict what ordinary English speakers would express, not speaking metaphysically, by uttering 'There are tables' - if, as he asserts, it does not contradict what they would express, not speaking as metaphysicians, by uttering 'there are two valuable eighteenth century antique tables in the next room'.

With what right then does van Inwagen use this negative existential sentence of ordinary English to express the proposition he does express by it? Why should this proposition, of the infinite number of propositions consistent with the ordinary language assertion 'there are tables' (e.g., the ones I would express by 'there are dogs', 'there are no 
longer any dodos', 'there never were any unicorns'), be expressed in the form 'there are no tables'? And how are we to identify, of the innumerable true propositions consistent with the beliefs the ordinary man would express, in the business of everyday life (van Inwagen 1990: 102), by uttering sentences that start 'there are ... tables ...' the one van Inwagen expresses when he asserts 'there are no tables'?

Van Inwagen tries to dispel the reader's misgivings here by appeal to analogous cases, the most developed of which is the fable of the bligers. ${ }^{8}$

English-speaking settlers in the hitherto unpeopled land of Pluralia observe what appear to them to be black tigers. They coin the term 'bliger' for these animals and occasionally comment on their activities (only occasionally because bligers keep their distance and so the settlers seldom need to think of them). In fact, in a way, there are no bligers. A bliger is really six animals combined together. Its 'legs' are four monkey-like creatures, its 'trunk' a sort of sloth, and its 'head' a species of owl. Any six animals of the various species can combine temporarily to form a bliger. The illusion is amazing and the settlers are taken in.

Now van Inwagen suggests that his assertion, speaking as a metaphysician, of the proposition he expresses by saying 'there are no tables', is on a par with the assertion of a foreign zoologist who a few centuries after the settlement discovers the optical illusion and reports it (to his zoological collegues or to the settlers) by saying 'there are no bligers'.

However, although it is clear enough what is going on in the case of the bligers, it is not clear how the analogy helps van Inwagen's case. In fact, it is clear that it does not. For even if the settlers continue to use the term 'bliger' after they have been informed of the discovery, the proposition they originally used the sentence 'there are bligers' to assert,

\footnotetext{
${ }^{8} \mathrm{He}$ also gives the Copernican analogy, but this is less close (the corresponding sentences are not grammatically existential). Anyway, this has been definitively refuted by Mackie (1993).
} 
namely, the existence of animals like tigers, but black in colour, has been discovered to be false. And, crucially, it has been discovered that they had false beliefs about how things were related at the level of simples (for they falsely believed that in the regions they thought of as 'containing bligers' simples were related amongst themselves much as they were in the location of tigers - we can suppose that they have detailed knowledge of the anatomy, physiology, biology, biochemistry etc., of tigers). It is appropriate for the zoologist to report his discovery by using the sentence 'there are no bligers' because he is reporting that the settlers's beliefs about how things are at the level of simples is mistaken - they have been taken in by an optical illusion. So it is appropriate for the zoologist to report his discovery in this way because he can use this sentence to express that simples are not, in the regions the settlers would describe as 'containing bligers', related to one another as the settlers believe they are, that is, that not everything at the level of simples is as they believe. However, nothing van Inwagen says gives reason for supposing that things are not, at the level of simples, exactly as the ordinary man, who is prepared to assert in the business of everyday life sentences beginning 'There are ... tables ...', believes them to be. In fact, it is part of van Inwagen's position precisely that he and I (who am such an ordinary man) might well agree entirely about how things are arranged at the level of simples (we might disagree for irrelevant reasons, if we have had different scientific educations, for example). So while I know what the foreign zoologist means by reporting to his colleagues 'there are no bligers', i.e., that the regions of which the settlers would say they 'contain bligers' actually contains simples arranged among themselves in a way that would be a surprise to them if they were to come to know it, I do not know, in the same way, what van Inwagen means by saying 'there are no tables'. In fact, one thing I can be sure he does not mean is that regions of which I would say 'they contain tables' contain simples arranged amongst themselves in a way that would surprise me if I were to learn of it. For he thinks that any such region contains simples 
arranged 'tablewise', i.e., arranged amongst themselves in a way such that if they knew of it, believers in tables like myself would find entirely unsurprising (there are, by contrast, according to van Inwagen, no simples arranged 'bligerwise' in Pluralia; it is just an optical illusion that there are).

Van Inwagen's tale of the bligers does not, then, persuade me that the Denial may be true. I therefore prefer to tollens van Inwagen, and draw from his argument the conclusion that a plenitudinous (weakly) pluralist ontology is an easy consequence of our ordinary, moderately scientifically educated, beliefs - and should be endorsed. ${ }^{9}$

Word Count: 3,699

\section{References}

Hirsch, T. 1993 Peter van Inwagen's Material Beings. Philosophy and Phenomenological Research 53(3): 687 - 91

Merricks, T. 2001 Objects and Persons. Oxford: Clarendon Press Mackie, P. 1993 Ordinary Language and Metaphysical Commitment. Analysis 53 (4):243 251

Van Inwagen, P. 1990 Material Beings. Ithaca: Cornell University Press

\footnotetext{
${ }^{9}$ I am grateful to an anonymous reviewer for helpful comments
} 